\title{
Empowering Minority Women: Autonomy versus Participation
}

\author{
Andrea Baumeister \\ Politics \\ School of Arts and Humanities \\ University of Stirling \\ atb1@stir.ac.uk \\ Tel.: 01786465727 \\ Fax: 01786467581
}

\begin{abstract}
Feminist attempts to empower women within their own cultural traditions have employed two broad strategies: authentic choice and participation. This paper argues that the methodological problems that beset the authentic choice strategy tell in favour of the participation approach. However, proponents of the participation strategy have failed to pay sufficient attention to the background conditions that need to be met if women are to make effective use of the institutional mechanisms their models advocate. If women are to be effective political agents at least some of the most serious structural inequalities that women face must be addressed. A nuanced statement of the participation strategy must therefore take account of long-standing feminist concerns regarding economic equality and access to resources. While this approach falls short of the demanding conditions for democratic citizenship implicit in the authentic choice strategy, it none the less places significant limits on the scope of participatory strategies and links the goal of empowering women within their own cultural traditions to wider feminist struggles to secure greater economic equality for women in general.
\end{abstract}

Key Words: Gender Equality, Cultural Justice, Nussbaum, Friedman, Deveaux, Shachar. 


\section{Empowering Minority Women: Autonomy versus Participation}

Recent feminist discourses regarding gender equality and cultural justice have focused on the need to empower minority women within their own cultural traditions. Here it is helpful to distinguish between two broad strategies: authentic choice and participation. While the former conceives of empowering women in terms of their capacity to control their lives and to exercise choice, the latter focuses on the need to ensure that women are properly represented in decision and policy-making procedures. Both strategies identify potentially important aspects of empowerment. However, the difficulties that beset even sophisticated versions of the authentic choice strategy, such as Martha Nussbaum's (1999) capability approach and Marilyn Friedman's (2003) consent-based model, point to significant methodological problems inherent in any appeal to conditions of choice as a strategy for empowering women within their own cultural traditions. In the light of such concerns feminists may find it helpful to shift their focus from attempts to define the background conditions that enable women to freely endorse or reject existing cultural roles and practices to the political processes that define and articulate these cultural roles and expectations. While the participation strategy proposed by writers such as Monique Deveaux (2006) and Aylet Shachar (2001) promises to provide new institutional mechanisms that enable women to challenge prevailing cultural roles and power relations, both Deveaux and Shachar struggle to define the background conditions that need to be met for women to make effective use of the opportunities for participation and voice that their models aim to facilitate. These difficulties point to the need for a more nuanced and carefully delineated statement of the participation strategy. In line with Nancy Fraser's (2003) call for feminists to reconnect discourses regarding recognition and representation with long-standing concerns relating to social and 
economic equality, this paper argues that vulnerable group members such as women will only be able to make effective use of the opportunities to participate in decisionmaking if serious structural inequalities such as a lack of education and economic deprivation are addressed. This analysis suggests that an effective strategy for empowering minority women needs to incorporate a redistributive dimension in addition to the concerns with recognition and representation that inform the models proposed by Deveaux and Shachar. While this approach falls well short of the rather demanding conditions for democratic participation implicit in the authentic choice model, it none the less places more significant limits on the scope of participatory strategies than proponents of this approach acknowledge. It also links these struggles to wider feminist discourses regarding better access to resources for women in general.

\section{Empowerment as 'authentic choice'}

Martha Nussbaum's capability approach and Marylin Friedman's consent based model constitute probably the two most prominent examples of the authentic choice strategy. While both Nussbaum and Friedman regard respect for women's actual choices, values and cultural attachments as important values, both stress that desires and preferences formed under unjust social conditions cannot be taken at face value. Many preferences, desires and emotions that influence the choices of individuals are learned in society and are shaped by social norms. Indeed, as Nussbaum (1999:11) notes 'people usually adjust their desires to reflect the level of their available possibilities' and hence can fail to form desires for things their circumstances have placed out of reach. After all women frequently internalise the norms of their own oppression. For example, women who have been denied access to education or 
employment outside the home 'may be slow to desire these things, because they may not know what they are like or what they could possibly mean in lives like theirs' (Nussbaum, 1999:11). Indeed, unjust or oppressive social conditions 'may deform the nature of a person's concern for herself' and may lead her 'to value or seek the very person or circumstances that keep her in oppressive conditions' (Friedman, 2003:19). From this perspective a feminism that seeks to empower women within their own cultural tradition should first and foremost aim to secure for all women the background conditions that enable them to make authentic choices. On Friedman's account this entails ensuring that women have access to a 'significant and morally acceptable array of alternatives', are 'able to make choices relatively free from coercion, manipulation and deception', and have the opportunity 'to develop, early in life, the capacities needed to reflect on their situations and make decisions about them' (Friedman 2003:188). On this account for choices to be authentic they must accord with the deeper wants and commitments that an agent has freely and selfreflectively endorsed. Similarly for Nussbaum (1999:46)

'a woman's affiliation with a certain group or culture should not be taken as normative for her unless, on due consideration, with all her capabilities at her disposal, she makes the norm her own'.

Crucial in this regard is Nussbaum's emphasis on autonomy and critical reason in clause 6 of her list of capabilities. Thus to be able to make informed choices women must be allowed to develop their capacity for practical reason, so that they can 'engage in critical reflection about the planning' of their own lives (Nussbaum, 1999:41).

While this emphasis on choice places Nussbaum and Friedman within a broadly liberal paradigm, both stress that their approaches are compatible with a wide variety 
of ways of life, including traditional non-liberal conceptions of the good. Thus, Friedman argues that her conception of content-neutral autonomy only requires that the background conditions for autonomous choice are met and does not demand that the content of what is chosen is itself consistent with the ideal of autonomy. Autonomy does not require a rejection of or distancing from one's traditions and attachments. Indeed, 'even preferences formed under oppressive social conditions can be the basis of autonomous behaviour if they represent what someone reaffirms as deeply important to her upon reflective considerations and she is able to act effectively on these concerns' (Friedman 2003:25). Hence for Friedman (2003:191) 'the consent of women in a minority culture to their own cultural practices that seem to violate their rights provides, on the face of it, a significant degree of justification for the cultural practices in question, so long as that consent is content-neutrally autonomous'. Similarly Nussbaum stresses that her approach is compatible with a plurality of comprehensive doctrines of the good and respects the decisions of women to lead a wide variety of lives, perfecting some capabilities and capacities while neglecting others. Therefore, although Nussbaum (1999:70/1) believes that antiliberal feminists are unwise to 'jettison the liberal account of human essence in favour of an account that gives more centrality to "accidental" features such as religion or class or even gender', she stresses that her approach 'strives to leave space for these other identities'.

Yet, despite these claims, it remains doubtful whether the authentic choice strategy favoured by Nussbaum and Friedman can indeed provide a basis for empowering women that is compatible with the respectful recognition of cultural norms. Much of the debate in this regard has focused on whether or not Nussbaum's and Friedman's 
emphasis on critical reflection entails criteria for authentic choice which are ultimately too demanding. ${ }^{1}$ These concerns have given rise to a lively debate on how best to define the criteria for authentic choice. However, the tensions inherent in Nussbaum's distinction between capabilities and functioning and Friedman's differentiation between content-neutral and substantive autonomy arguably point towards more deep-seated methodological problems that are liable to compromise any appeal to the conditions of choice as a strategy for empowerment. As both Nussbaum and Friedman recognise, if the authentic choice strategy is to avoid the dangers of simply privileging liberal concerns and pre-occupations, it is vital to draw a clear distinction between the pre-requisites required to exercise choice and the substance or content of the options that individuals adopt. After all, if the authentic choice strategy is to be compatible with the respectful recognition of cultural norms, women must be free to choose a wide variety of lives, including cultural roles that minimise autonomy. Indeed, Nussbaum's desire to clearly differentiate between capabilities and functioning and Friedman's distinction between content-neural and substantive autonomy are both attempts to separate the exercise of authentic choice from the substance or content of what is chosen. Thus, according to Nussbaum, her list of capabilities is best understood as a 'list of opportunities for life functioning' and does not require that citizens act in certain valued ways or pursue a particular conception of the good. However, while this distinction between capabilities and functioning is theoretically impeccable, in practice it is difficult to sustain. After all, in practice 'freedom cannot be easily observed unless it has been exercised'

(Deneulin.2002:502). ${ }^{2}$ Consequently, often the most effective way of assessing whether a government has succeeded in providing citizens with the opportunity to develop all their core capabilities is to look at actual functioning. If, for instance, 
women refuse to go to literacy classes offered to them, it will be difficult to determine whether this reflects a free choice or is based upon internalised social norms and expectations regarding the status of women. Therefore, in practice the most readily accessible way of evaluating the effectiveness of a literacy programme is to look at the actual number of women who have learned to read. Nussbaum's persistent scepticism regarding the choices of women who endorse a life-style that limits their autonomy and her tendency to portray such preferences as signs of continued subordination and adaptive preference formation arguably reflect, at least in part, this slippage between capabilities and functioning. ${ }^{3}$

Friedman's distinction between substantive and content-neutral conceptions of autonomy gives rise to similar difficulties. Although only substantive accounts of autonomy require that the content of what is chosen is compatible with the ideal of autonomy, in practice the difficulties inherent in assessing whether or not the conditions for content-neutral autonomy have been met are liable to give rise to a slippage whereby only those choices that also approximate the ideal of substantive autonomy are recognised as procedurally autonomous. After all not only is it difficult to reliably assess in how far a person who continues to uphold traditional practices has critically reflected upon these traditions and is fully aware of alternatives, many forms of manipulation, coercion and deception are subtle and often difficult to quantify. As Friedman (2003:191/192) herself recognises 'the choices of women that deserve default respect are those made under conditions promoting the women's contentneutral autonomy' and there is liable to be much 'debate over what promotes or impedes autonomy in practice'. Because it may be difficult to establish whether women who continue to endorse traditional practices and life-styles genuinely had the 
opportunity to develop a more autonomous life, there is a danger that only the rejection of such a life-style will be taken as conclusive proof that the women indeed had, in Nussbaum's language the opportunity to develop the relevant capabilities or in Friedman's terms enjoyed the conditions for the exercise of procedural autonomy. Thus, in practice advocates of the authentic choice strategy may find it difficult to respect women's freedom to continue to endorse their traditional way of life and not to avail themselves of certain opportunities. Ultimately the authentic choice strategy is liable to continue to privilege typically liberal pre-occupations, choices and ways of life.

In the light of these difficulties feminists who seek to empower women within their own cultural traditions may find it helpful to shift their focus from the background conditions that enable women to freely endorse or reject existing cultural roles and practices to the social and political processes that define and articulate these cultural roles and expectations. Bearing in mind that cultural norms and roles shape the framework within which women act and delineate the options available to them, empowering women to challenge or to re-interpret the definitions of the cultural expectations that prevail within their community promises to transform gender relations within the community as a whole. For example, given that it will be very difficult indeed for individual women to resist a practice such as female genital cutting in a social environment in which it is intricately linked to the notion of marriageability, the most effective way to challenge the practice may be for women to employ social and political forums to question this linkage and to encourage the community as a whole to re-consider its notions of marriageability and women's sexuality. A successful campaign to eradicate the practice of genital cutting in 
Senegalese villages provides a good example of the extent to which changes to existing cultural practices can often be a collective action problem and highlights the importance of deliberative forums that enable those affected to explore the impact of current practices and to seek alternatives. In 1996 women from the village of Malicounda Bambara decided to campaign for the abolition of genital cutting in their village (Mackie 2000). The women had participated in the Tolstan basic education programme, which is a non-directive education programme aimed at providing 'skills and information that help people better define and pursue their own goals' and which offers women a forum in which they 'can safely engage in free and equal deliberation about real problems' (Mackie 2000:261). Through a process of discussion and information the women persuaded the villagers to agree a date by which they would all give up the practice. The villager's previous adherence to the practice appears to have been motivated mainly by the worry that if they abandoned the practice unilaterally their daughters would become unmarriageable. Given a reasonable assurance that others would act in the same manner, it became much easier for villagers to give up the practice. Moreover, the success at Malicounda Bambara created a snowball effect, in which 'from 1997 onwards, one village after another collectively abandoned the practice' (Philips 2007:46). As this example illustrates, social and political forums can play a vital role in enabling women to challenge existing norms and practices and to persuade the community as a whole to embrace change. It is this focus on the social and political processes that define and articulate cultural norms and expectations that is central to the participation strategy. 


\section{Empowerment as Participation}

Advocates of the participation strategy, such as Monique Deveaux (2006) and Aylet Shachar (2001), seek to empower women by creating new institutional mechanisms that facilitate critical debate about established cultural norms and practices. In contrast to the normative approach favoured by advocates of the authentic choice model, proponents of the participation strategy argue that disputes about gender and culture are primarily political and thus best analysed in terms of power. Indeed tensions between liberal norms and many of the cultural practices that have given rise to concern among feminists expose not just intercultural disputes. They often also highlight intracultural disagreements over the interpretation, meaning and legitimacy of particular norms. For example, in recent years there has been considerable debate within Jewish and Muslim communities regarding the origin, nature and interpretation of the communities' personal and family law (Shachar 2001). For proponents of the participation strategy such conflicts are often strategic or political in character reflecting interests and power relations both within the community and between the community and the wider society. Consequently such disputes are best resolved via a pragmatic approach that focuses on practical concerns and concrete consequences.

Although Deveaux and Shachar advocate quite different institutional mechanisms, both employ a broadly similar strategy, combining a degree of self-governance for minorities with mechanisms that enable traditionally marginalised and potentially vulnerable group members to challenge the existing power relations and dominant interpretations of norms and values within the group. To facilitate such challenges Deveaux invokes the principles of democratic deliberation, whereas Shachar employs the idea of joint governance. Thus, on Deveaux's model, conflicts about cultural 
practices that are at odds with the norm of gender equality should be addressed through deliberative forums, which encourage representatives from all parties affected by a particular issue - including representatives from women's groups - to give 'frank and concrete reasons in support of particular customs and proposals for or against change' (Deveaux 2005:349). According to Deveaux, the ensuing negotiations, bargaining and compromise will encourage critical refection upon the validity of participants' interests and will expose the motives of those who simply seek to maintain control over vulnerable members of their community. To ensure that potentially vulnerable group members such as women have a genuine opportunity to voice their concerns such deliberative processes must observe three key principles: non-domination, political equality and revisibility. While the principle of nondomination aims to guarantee that traditionally marginalised group members cannot be silenced through pressure tactics and oppression, the principle of equality seeks to ensure that "'extrapolitical and endogenous forms of influence, such as power, wealth and pre-existing social inequalities' cannot impact upon democratic deliberations (Deveaux 2005:350). Finally, the principle of revisibility stipulates that it should always be possible to revisit decisions at a later date.

In contrast to Deveaux's focus on policy formation within the political realm, Shachar employs a range of legal mechanisms to enable women who belong to minority groups whose norms differ from those encoded in state law to challenge discriminatory practices. Her innovative system of joint governance grants minority groups partial self-governance by inviting them to share jurisdiction in contested social arenas such as family law, criminal justice and education. At the same time her approach encourages both the state and the minority group to pay greater attention to 
the interests of vulnerable constituents such as women through the institution of clearly delineated and pre-agreed choice options. These allow individuals whose interests are being systematically ignored to choose, on an issue by issue basis, whether to have a particular matter adjudicated by the state or the minority group. Thus state and minority group have to compete for the loyalties of previously marginalised group members. The threat of selective exit on an issue by issue basis enables group members who bear a disproportionate burden under current arrangements to seek redress without having to renounce group membership. This raises the 'collective risks and costs of maintaining discrimination and subordination' as communities who do not respond to demands for change risk that members will choose to have disputed issues adjudicated by the state (Shachar 2001:125). Selective exit options therefore encourage groups to reinterpret and adapt existing rules and practices.

While Deveaux and Shachar seek to develop institutional mechanisms that enable potentially marginalised group members to challenge existing power relations, both also stress that the ensuing political and legal processes must respect participants' actual values and commitments and must not preclude non-liberal outcomes. Thus, Shachar argues that to ensure that there are no imbalances of power, state and minority groups ought to enjoy broad equality of status in terms of the allocation of jurisdictional authority. Indeed to address potential power imbalances between the minority and the state, the presumptions governing the initial negotiations regarding the allocation of sub-matters should favour the group. This can be achieved by allowing the minority to set the agenda or by guaranteeing it control over its preferred sub-matter in at least one social arena. Most importantly, for Shachar there are no 
constitutional essentials or fundamental liberal rights that cannot be subject to negotiation. ${ }^{4}$ Although Deveaux's model seeks to establish a set of pre-conditions for democratic deliberation, her approach also emphasises the need to respect the values and beliefs of members of minority groups. Thus, while Deveaux argues that deliberative processes must respect the principles of non-domination, political equality, and revisability, she stresses that her procedural account of democratic deliberation implies that 'group members may justly reject the imposition of an a priori norm of equality on the terms and outcomes of political debate (Deveaux 2006: 219). Indeed Deveaux's commitment to a procedural account of democratic deliberation together with her concrete examples of how deliberative processes can give rise to reforms that promote greater gender equality point to quite a minimal reading of the conditions for democratic participation. Such a minimal reading emphasises voice and the prevention of overt coercion, but does not require the elimination of all extrapolitical and endogenous forms of influence. For example, Deveaux cites the negotiations in South Africa in the 1990s leading up to the reform of customary marriages. However this case arguably does not meet Deveaux's formal definition of the pre-conditions for democratic participation. Not only did the participation of non-elected tribal leaders not sit well with the requirement to eliminate extra political forms of influence, such as power, wealth and pre-existing social inequalities, the resistance by at least some tribal leaders to the very idea that women should play a greater part in decision-making in South African society threatened to undermine the principle of political equality. ${ }^{5}$ As this example suggests in practice the conditions for democratic deliberation envisaged by Deveaux are liable to be significantly less stringent than her formal definition may suggest. Indeed a more minimal reading of the conditions for democratic deliberation reflects a certain 
realism about the character of actual political practices that sits well with the emphasis on pragmatism central to the participation strategy. After all to insist on eliminating the influence of all extrapolitical factors such as power, wealth and preexisting social inequalities would risk prescribing an over-idealised and ultimately overly demanding conception of political deliberation that threatens to impose upon cultural and religious communities conditions that are rarely, if ever, met in democratic deliberations in liberal societies.

Deveaux's and Shachar's desire to design institutions that can facilitate non-liberal outcomes sits well with a genuine respect for the actual choices, values and commitments of minority groups and thus promises to eliminate some of the pitfalls that beset the autonomy approach. However, the ensuing institutional arrangements potentially pose considerable challenges for vulnerable group members. If state and minority are to be equal partners and if extrapolitical and endrogenous forms of influence cannot be entirely eliminated from formal political deliberations, traditionally marginalised group members will need to be confident and vigorous in defence of their own interests. Only if these conditions are met will women be able to make effective use of institutional mechanisms such as Shachar's choice options or Deveaux's deliberative forums. Indeed, given the commitment to respect the existing values of participants, proponents of the participation strategy need to be mindful of the dangers of simply re-inscribing existing power relations. Therefore, both Deveaux and Shachar ought to give careful consideration to the background conditions that shape women's agency. Yet it is in this regard that their approach remains deeply troubling. 
In an attempt to side-step the difficulties that beset attempts to cash out agency in terms of autonomy, Deveaux (2006: 124) proposes an account of agency that focuses on the indirect ways in which women in traditional communities tend to exercise agency through small decisions such as acts of social transgression, subversion or indirect resistance, such as the temporary abdication of 'domestic and caretaking duties'. On this account, agency constitutes 'any activity or expression that signals a response to a prevailing social norm, custom, role or arrangement' which reflects or helps to 'secure something that the person has cause to value' (Deveaux 2007:153/157). Faced with the worry that an account of agency that focuses on indirect acts of resistance, transgression and subversion will be insufficient to tackle the problems associated with adaptive preferences, Deveaux (2006:93) argues that in liberal democracies worries about adaptive preferences have less purchase, since 'the majority culture offers a range of life options for women, and few groups are so isolated that their members cannot imagine other possible lives'. Similarly Shachar argues that in a liberal society the state's exercise of authority in its designated submatters will be sufficient to ensure that women will have access to the opportunities and resources to develop the knowledge and to obtain the means necessary to pose a real threat of selective exit.

Shachar and Deveaux may well be right to point to the beneficial effects of a wider liberal framework. However, both writers fail to consider the potential impact of their proposals upon the very background conditions they invoke to secure women's agency. Given the dynamics inherent in Deveaux's and Shachar's models, it is far from certain that once these models are implemented that the general background conditions will indeed remain sufficient to ensure that women from minority 
communities would be able to develop a robust sense of agency. To mount a successful challenge to existing power relations entails not just an awareness of potential alternatives and the opportunity to participate in deliberative processes, but also the confidence and sense of independence to state proposals that will, at least initially, be resisted by the dominant factions within the minority. Arguably the acquisition of such skills requires, at the very least, an education system that ensures that all children are taught a broad range of skills and that fosters cross-cultural contact.

Education, however, has proven to be a particularly contentious point in cross-cultural disputes. Education plays an important role in preserving, maintaining and transmitting cultural and religious values and beliefs both through direct teaching and through the general school ethos. Minority communities have persistently challenged and resisted educational provisions that they fear may undermine their ability to initiate their children into the community's established values, traditions and norms. Potentially contentious issues in this area are numerous including the language of instruction, demands for exemptions from contested educational provisions, such as sex education, the content and character of religious education, and demands for state support to establish separate schools with a curriculum and ethos supportive of community values and beliefs. ${ }^{6}$ In the light of these concerns both Deveaux and Shachar hold that respect for the actual values and commitments of minorities entails that educational provisions must be subject to the principles of deliberation and power sharing. Indeed Deveaux is explicitly critical of liberal conceptions of autonomy that require the rejection of religious schooling that reinforces traditional sexual roles. ${ }^{7}$ The potential difficulties inherent in such a position are exemplified in Shachar's 
attempt to apply the principles of transformative accommodation to the area of religious education. Under Shachar's proposals, religion is to be treated as an educational sub-matter alongside civic education. While the state controls the civic education component, religious minorities are allowed to determine the nature and content of religious education classes. Although children from different denominational groups attend the same school and share the same civic education, for the purpose of religious instruction classes (normally two to three hours per week) students are broken up into different classes according to their religious affiliation. This allocation of authority is to be accompanied by a series of choice options. Not only should it be possible to 'opt in' and 'opt out' of religious education, to address potential conflicts between the commitments and educational ethos that underpins the civic curriculum and tenets central to the values of religious minorities Shachar proposes 'opt in' and 'opt out' choices across a range of subjects of instruction.

Granting religious communities control over the content of a limited number of religious education classes within the context of an overwhelmingly state controlled civic education would arguably not unduly impinge upon women's capacity to develop a broad range of skills and capabilities. However such a limited proposal is unlikely to satisfy many religious communities who have persistently expressed concern regarding the overall ethos of their children's education. Yet, to permit in the face of such concerns a broad range of 'opt out' options, as proposed by Shachar, or to uphold the right to a religious schooling that reinforces traditional gender roles as advocated by Deveaux, runs the risk of undermining one of the key background conditions that will enable women to become effective participants in the institutional processes that are key to the participation strategy. For example, if the exercise of the 
general choice options proposed by Shachar is left in the hands of parents, some may wish to withdraw their children from any aspect of the curriculum that potentially challenges their religious commitments. This could affect a very broad range of curricular matters. Indeed 'even the most basic forms of liberal civic education give rise to complaints' (Macedo, 1995: 470). For example in the case of Mozert v. Hawkins (1983) 'born again' Christian families in Tennessee argued that a primary school reading programme designed to present children with a variety of religious perspectives denigrated the truth of their beliefs by presenting material in an evenhanded and uncommitted fashion. ${ }^{8}$ Faced with such worries Shachar may, of course, wish to argue that general educational choice options should only be instituted once pupils themselves are capable of exercising them. Indeed her only example of a potential general educational opt out, sex education, suggests that this may well be what she has in mind. If this is so, Shachar's proposals regarding religious education imply that from the age of 14 onwards students should be able to determine for themselves whether or not to exercise their right to opt out. However, it is doubtful whether children who are still economically dependant on their parents would indeed be able to make free choices. Given the typical power relations within families there must surely be a real danger that children will be subject to both informal and formal parental pressures to 'choose' in accordance with their parents' wishes and cultural expectations.

The difficulties associated with Shachar's and Deveaux's positions regarding education highlight the general tension inherent in their overall strategy between, on the one hand, the desire to respect the actual values and beliefs of participants in institutional processes and, on the other hand, the commitment to empower women to 
challenge the existing power relations within their community. Although the emphasis on internal debate and contestation and the desire not to preclude non-liberal outcomes sits well with the aims and aspirations of many indigenous feminists movements, ultimately both Deveaux and Shachar fail to adequately define the background conditions that need to be met for women to be effective actors within the institutional frameworks central to the participation strategy.

\section{Resources, Participation and Agency}

While the difficulties that surround the authentic choice model suggest that proponents of the participation strategy are right to be weary of attempts to cash out agency in terms of expressly liberal values such as personal autonomy or authentic choices, they typically underestimate the impact of their proposals upon the very background conditions they invoke to ensure that women develop the capacities for effective participation. In pluralist liberal democracies worries about adaptive preferences may well have less purchase. However, once the institutional mechanisms favoured by advocates of the participation strategy such as Deveaux and Shachar are applied across the wide range of potentially contested issues, the ensuing policies may well alter the background conditions in such societies in ways that may undermine rather than enhance women's capacity for agency. In this context the potential difficulties inherent in the models developed by Shachar and Deveaux are by no means confined to issues surrounding education, but may impact upon a host of structural inequalities, such as financial independence and economic security. For example, if minorities are simply left to negotiate rules regarding inheritance and divorce within the context of Deveuax's purely procedural deliberative framework, 
there is no guarantee that the ensuing policies will indeed protect women's economic interests. Similarly, while in her discussion of marriage and divorce, Shachar envisages that under transformative accommodation the state would retain control over economic and custodial matters, minorities presented with the opportunity to exercise joint governance may not endorse such a division of jurisdictional authority. In the absence of a theoretical framework that clearly distinguishes between constitutional essentials and practices, rights and entitlements that can be subject to the jurisdiction of the minority group, Shachar cannot guarantee that the allocation of jurisdictional authority will follow a particular pattern. While Shachar's proposed system of selective choice options offers additional protections for women, there remains a real risk that the initial allocation of jurisdictional authority will have a detrimental impact upon the background conditions such as education, economic security and financial independence that enable women to make effective use of the option of selective exit.

These worries suggest that ultimately proponents of the participation strategy cannot entirely sidestep the complex questions surrounding women's capacity for agency that are central to the authentic choice model. If women are to make effective use of the opportunities for democratic participation proposed by Deveaux or the selective choice option advocated by Shachar, they must be able to develop the capabilities and capacities that enable them to be effective political agents. In this regard proponents of the authentic choice model such as Nussbaum (1999) and Friedman (2003) point quite rightly to education and financial independence as important goals for women. This is not to dismiss the serious difficulties associated with the substantive liberal values inherent in the authentic choice model. On the contrary, rather than frame the 
background conditions that delimit the scope of institutional mechanisms for deliberation or power sharing in terms of autonomy or authentic choice, feminists attracted to the participation strategy may well find it more useful to engage with alternative approaches that draw upon long-standing feminist concerns regarding economic equality and access to resources. These concerns continue to play an important role in the work of feminist theorists such as Nancy Fraser (2003). Indeed the difficulties which beset even sophisticated models of the participation strategy lend weight to Fraser's call for a need to reconnect recent feminist discourses regarding recognition and representation with previous feminist concerns relating to social and economic equality. As Fraser rightly notes, both maldistribution and misrecognition can undermine women's capacity to participate on par with others in political institutions. To address the complex interaction between maldistribution and misrecognition Fraser (2004:127) proposes a broad and capacious conception of justice centred around the principle of parity of participation, which stipulates that 'justice requires social arrangements that permit all (adult) members of society to interact with one another as peers'. In this context Fraser (2003:36) distinguishes between the objective conditions of participatory parity, which 'preclude forms and levels of economic dependence and inequality that impede parity of participation' and intersubjective conditions of participatory parity, which prohibit 'institutionalised norms that systematically depreciate some categories of people and the qualities associated with them'. While the former requires redistribution, the latter is to be addressed through recognition. As Fraser (2004:140) rightly notes, although maldistribution and misrecognition are 'thoroughly imbricated' and impact upon one another in a variety of ways, these two dimensions cannot simply be collapsed into one another. On the contrary 'each dimension has some relative independence from 
the other' (Fraser: 2007: 26). Thus 'gender maldistribution is not simply a by-product of status hierarchy - nor is gender misrecognition wholly a by-product of economic structure' (Fraser: 2007: 26). For example, oppression can be social and psychological as well as economic and even comparatively well-off women can potentially be as seriously oppressed as those who lack economic power. ${ }^{9}$ By the same token the eradication of social and psychological oppression in itself is unlikely to be sufficient to overcome economic inequality. A commitment to gender equality, therefore, requires both redistribution and recognition.

This account of the interplay between recognition and redistribution combined with Deveaux's and Shachar's sophisticated analysis of the complex relationship between gender equality and cultural justice can arguably provide the foundations for a more nuanced and carefully delineated statement of the participation strategy that is sensitive to the need to secure the background conditions essential to women's capacity for effective political agency. The institutional mechanisms advocated by Deveaux and Shachar are clearly well placed to address what Fraser terms the intersubjective conditions of participatory parity. Indeed, the manner in which Deveaux and Shachar combine a degree of self-governance for minorities with mechanisms that enable women to challenge existing power relations and dominant interpretations of norms and values echoes Fraser's (2004:138) preference for nonreformist reform; that is to say policies that have

'a double face: on the one hand, they engage people's identity and satisfy some of their needs as interpreted within existing frameworks of recognition and distribution, on the other hand, they set in motion a trajectory of change in which more radical reforms become practicable over time'. ${ }^{10}$

Moreover, the sophisticated institutional models proposed by Deveaux and Shachar offer important insights into how to secure genuine recognition for women within 
their own cultural traditions that are absent from Fraser's analysis. Although Fraser recognises the need to critically evaluate the impact of claims for cultural recognition upon participatory parity at intra-group level, she fails to systematically explore the complex interplay between conceptions of gender equality and culture. Thus, while Fraser acknowledges that such judgements require democratic processes of public debate, she fails to explore the extent to which intragroup participatory parity is depended upon the development of participatory mechanisms specifically designed to facilitate the development of culturally sensitive conceptions of gender equality. ${ }^{11}$ For example, in her discussion of the French controversy surrounding the foulard Fraser (2007) is sympathetic to the argument that the meaning of the scarf is highly contested and that the foulard should therefore not simply be seem as a marker of women's subordination. However, she offers no guidance on how such processes of contestation can be brought to bear to facilitate the development of culturally sensitive conceptions of gender equality and to secure genuine recognition for women within their own cultural traditions. In this regard the mechanisms proposed by Deveaux and Shachar constitute a welcome addition to Fraser's analysis. However these mechanisms will only be effective if the background conditions are safeguarded that enable women to make good use of opportunities to challenge existing power relations. Here Fraser's emphasis on the objective conditions of participatory parity highlights the importance of economic security and independence as a vital prerequisite for effective democratic agency. As Fraser rightly notes, maldistribution and misrecognition can neither be insulated from each other nor can one be reduced to the other and policies designed to secure recognition are unlikely to succeed in the absence of a firm focus on the economic factors that can secure the objective conditions for parity of participation. Thus, just as policy analysts have argued that 
'the surest way to raise poor women's status in developing countries is to provide them access to paid work (Fraser 2004: 141), so arguably one of the best ways of ensuring that women's voices are heard in participatory forums is to make sure that women enjoy economic security and independence. This suggests that rather than cash out the background conditions for democratic agency in terms of autonomy or authentic choice, proponents of the participatory strategy should focus on the conditions that ensure that all participants enjoy adequate financial security and economic independence. Once these objective conditions of participatory parity are addressed, the models proposed by Deveaux and Shachar are arguably well placed to enable women to challenge existing power relations and established interpretations of norms and values within their own communities. Furthermore, since access to economic resources can quite readily be measured, a focus on economic independence arguably avoids the most serious methodological difficulties inherent in any attempt to determine whether or not a woman's particular choices meet the conditions of autonomy or authenticity. Such an approach would, for instance, entail ensuring that women have access to an education that enables them to acquire marketable skills rather than the more complex and far-reaching goal of educating for autonomy.

This approach has important implications for both the scope of the participatory strategy and the relationship between such mechanisms for empowering minority women and wider feminist struggles for gender equality. Although Deveaux acknowledges that a commitment to equal political participation may well require state intervention to address structural inequalities such as economic deprivation and lack of education, neither she nor Shachar recognise the limits such pre-requisites set for the scope of the participatory mechanisms they advocate. While an emphasis on 
financial security and economic independence falls well short of the rather demanding conditions for democratic participation implicit in Nussbaum's and Friedman's authentic choice model, it none the less implies that the liberal framework that both Deveaux and Shachar presume as a backdrop to their approach will need to be more substantive and the scope for democratic deliberation and joint governance more limited than either theorist acknowledges. Not only will the influence of minorities over questions of education have to be limited to ensure that all women can acquire a broad range of marketable skills, the state will have to retain control over issues which can impact directly upon women's financial security and economic independence. Thus, for example, on this account, financial and custodial issues relating to questions of marriage and divorce or rules regarding inheritance and property ownership fall outside the scope of the issues that can be determined via participatory mechanisms and democratic deliberation within minority groups. The liberal state has an obligation to secure for all citizens the objective conditions of parity of participation and must therefore ensure that women's economic interests in these areas are protected. This, of course, still leaves considerable scope for disagreements regarding the role of women that can be settled through institutional mechanisms such as Deveaux's model of democratic deliberation or Shachar's proposals for joint governance. However, such mechanisms will operate within a distinctly liberal framework, explicitly designed to safeguard the independence of all participants. This is not to suggest that current provisions in western liberal democracies adequately safeguard the needs of all women in this regard. Rather it places the question of empowering women within minority communities within the context of wider feminist struggles in liberal democracies for greater economic equality and financial security for women in general. 
What emerges from this analysis is a three-dimensional conception of empowering minority women, which incorporates redistribution, recognition and representation. ${ }^{12}$ While the redistributive dimension links the struggles of minority women to wider feminist campaigns for financial security and economic equality for women in general, the dimension of recognition highlights the 'cultural discursive' aspect of gender and the complex interactions between conceptions of gender equality and cultural values and norms. Whereas the former aims to secures the background conditions that ensure that all women enjoy the independence vital for effective political agency, the latter highlights the need for mechanisms that enable minority women to exercise this political agency to develop culturally sensitive conceptions of gender equality that are attuned to their needs, values and commitments. Finally, the representational dimension draws attention to the political processes and decisionmaking procedures that 'frame' the issues that affect women's lives. In this context the work of proponents of the participation strategy such as Deveaux and Shachar rightly highlights the importance of new democratic forums that can offer an effective remedy to the dangers of 'misframing' that can occur when majority evaluative and decision-making processes are employed to address contentious issues regarding gender equality within minority cultural communities. If the needs and aspiration of minority women are not be misconstrued, minority women must be empowered to make their voices heard. Indeed once carefully delineated and placed within a distinctly liberal framework designed to safeguard women's economic security and independence, the participatory mechanisms championed by Deveaux and Shachar are well placed to empower women to challenge existing power relations within their cultural traditions and to develop distinctive, culturally sensitive conceptions of gender equality. 


\section{Conclusion}

The difficulties that beset even sophisticated accounts of the authentic choice strategy, such as the models advocated by Nussbaum and Friedman point to significant methodological problems inherent in any appeal to the conditions of choice as a strategy for empowering women within their own cultural traditions. In the light of these concerns feminists may wish to shift their focus from attempts to define the background conditions that enable women to freely endorse or reject existing cultural roles and practices to the social and political processes that define and articulate these cultural roles and expectations. While the participation strategy proposed by writers such as Deveaux and Shachar promises to provide new institutional mechanisms that enable women to challenge existing power relations and the dominant interpretations of norms and values that define their cultural communities, women will only be able to make good use of such opportunities for participation if they have been able to develop the capacities and capabilities that enable them to be effective political agents. These worries suggest that proponents of the participation strategy will not be able to entirely avoid the complex questions regarding the background conditions that facilitate women's agency central to the authentic choice model. None the less the serious difficulties associated with attempts to cash out agency by an appeal to distinctly liberal values such as personal autonomy or authentic choices cannot be readily dismissed. In their search for an alternative account of the background conditions that secure women's agency, feminists attracted to the participation strategy may find it helpful to re-engage with long-standing feminist concerns with economic equality and access to resources. Such an approach entails a three dimensional conception of empowering minority women, which incorporates redistribution, recognition and representation. While the redistributive dimension 
secures the background conditions for effective political agency and links the question of empowering women within their own cultural traditions to wider feminist struggles

for economic equality, the recognition strand highlights the need for culturally

sensitive conceptions of gender equality. Finally the representative dimension aims to

ensure that minority women can give effective political expression to their own

aspirations and concerns. While such an approach falls short of the demanding

conditions for democratic participation implicit within the authentic choice model, it

none the less places significant limits on the issues that can be settled solely by an

appeal to democratic participation.

\footnotetext{
Endnotes

${ }^{1}$ For critiques of Friedman's account of conditions for authentic choice see, for example, Narayan (2002), Mackenzie (2007) and Deveaux (2007). For critiques of this aspect of Nussbaum's capabilities approach see, for example, Deneulin (2002), Phillips (2001) and Wolff (1995).

${ }^{2}$ While Deneulin develops this critique in the context of her discussion of Sen's capability approach, it arguably applies just as much to Nussbaum's model.

${ }^{3}$ For a critique of Nussbaum's analysis of the choices of women who endorse life-styles that limit their autonomy see Phillips (2001) and Wolff (1995).

${ }^{4}$ On this point also see Benhabib 2002.

5 As Okin (2005) notes, Deveaux's formal criteria for democratic participation may be read to favour a much more interventionist stance. On such a reading the principle of equality entails careful attention to who is to act as a representative and how representatives are chosen, while the principle of nondomination is taken to require wide-ranging intervention in the family and women's position in society. While critics like Okin may welcome such an expansive reading and the extensive intervention associated with it, it cannot be readily reconciled with Deveaux's aim to offer a procedural account of democratic deliberation that respects the values of participants and engages with their strategic interests. A minimalist reading of the formal criteria of democratic participation is more compatible with Deveaux's overall goals than the strong reading favoured by Okin.

${ }^{6}$ For detailed critical discussions see, for example, Macedo (1995) and Barry (2001).

${ }^{7}$ In this context Deveaux (2007) explicitly rejects Marylin Friedman's account of procedural autonomy.

${ }^{8}$ For a discussion of this case see Macedo (1995).

${ }^{9}$ I like to thank Monica Mookherjee for this example.

${ }^{10}$ Fraser regards non-reformist reforms as a potentially valuable tool for resolving the difficulties and tensions that surround both affirmative and transformative strategies. While affirmative strategies 'aim to correct inequitable outcomes of social arrangements without disturbing the underlying social structures that generate them', transformative strategies expressly aim to restructure the 'underlying generative framework' (Fraser 2004:133). Although transformative strategies avoid the risk of reifying collective identities associated with affirmative strategies, calls for the restructuring of the underlying social framework often appear remote from the immediate concerns of those who suffer from maldistribution or misrecognition. Fraser contents that in practice this distinction between affirmative and transformative strategies is not absolute and that non-reformist reforms can be employed to generate policies, which, while accessible to those who suffer from maldistribution and misrecognition, avoid the dangers of reification.

${ }^{11}$ Fraser (2007: 31) argues that in cases where demands for the recognition of minority cultural practices appear to be at odds with the demands of gender justice the principle of participatory parity must be applied at both the inter and the intra group level. Thus 'claimants must show, first, that the
} 
institutionalization of majority cultural norms denies them participatory parity and, second, that the practices whose recognition they seek do not themselves deny participatory parity to others, as well as to some of their own members'.

12 This tripartheit conceptualisation draws on and adapts Fraser's (2005) distinctions. In contrast to the definition of 'misframing' adopted here, Fraser's (2005: 305) work focuses on questions of transnational justice and the potentially pernicious effects that can arise when the 'state territorial frame is imposed on transnational sources of injustice'.

\section{Bibliography}

Barry, B. (2001) Culture and Equality. Cambridge: Polity Press.

Benhabib, S. (2002) The Claims of Culture Equality and Diversity in the Global Era. Princeton: Princeton University Press.

Deneulin, S. (2002) Perfectionism, Paternalism and Liberalism in Sen and Nussbaum's Capability Approach. Review of Political; Economy 14 (4): 497-518.

Deveaux, M. (2005) A deliberative approach to conflicts of culture. In: A. Eisenberg, and J. Spinner-Halev, (eds.) Minorities within Minorities Equality, Rights and Diversity.Cambridge: Cambridge University Press: 340-62.

Deveaux, M. (2006) Gender and Justice in Multicultural Liberal States. Oxford: Oxford University Press.

Deveaux, M. (2007) Personal autonomy and cultural tradition. In: B. Aneil, M. Deveaux, R. Dhamoon and A. Eisenberg (eds.), Sexual Justice/Cultural Justice, London: Routledge: 139-165.

Fraser, N. and Honneth, A. (2003) Redistribution or Recognition? A PoliticalPhilosophical Exchange. London: Verso.

Fraser, N. (2004) Institutionalising Democratic Justice: Redistribution, Recognition and Participation. In: S. Benhabib and N. Fraser (eds.), Pragmatism, Critique, Judgement Essays for Richard J. Bernstein. Cambridge, Massachusetts: MIT Press: 125-147.

Fraser, N. (2005) Mapping the Feminist Imagination: From Redistribution to Recognition to Representation. Constellations 12 (3): 295-307.

Fraser, N. (2007) Feminist Politics in the Age of Recognition: A Two-Dimensional Approach to Gender Justice. Studies in Social Justice 1 (1): 23-35.

Friedman, M. (2003) Autonomy, Gender, Politics. Oxford: Oxford University Press.

Mackenzie, C. (2007) Relational autonomy, sexual justice and cultural pluralism. In: B. Arneil, M. Deveaux, R. Dhamoon and A. Eisenberg (eds.), Sexual Justice / Cultural Justice, London: Routledge: 103-121. 
Macedo, S. (1995) 'Liberal Civic Education and Religious Fundamentalism: The Case of God v. John Rawls?’ Ethics 105 (3): 468-96.

Mackie, G. (2000) Female Genital Cutting: The Beginning of the End. In: B. ShellDuncan and Y. Hernlund (eds.), Female "Circumcision" in Africa Culture,

Controversy and Change. Boulder, Colorado: Lynne Reiner: 253-281.

Narayan, U. (2002) Minds of their Own: Choices, Autonomy, Cultural Practices, and Other Women. In: L.M. Antony and C.E. Witt (eds.), A Mind Of One's Own Feminist Essays on Reason and Objectivity. Oxford: West View Press.

Nussbaum, M. (1999) Sex and Social Justice. Oxford: Oxford University Press.

Okin, S. (2005) Multiculturalism and feminism: no simple question, no simple answer. In: A. Eisenberg and J. Spinner-Halev, (eds.), Minorities within Minorities Equality, Rights and Diversity. Cambridge: Cambridge University Press: 67-89.

Phillips, A. (2001) Feminism and Liberalism Revisited: Has Martha Nussbaum Got It Right?. Constellations 8 (2): 249-66.

Phillips, A. (2007) Multiculturalism without Culture. Princeton: Princeton University Press.

Shachar, A. (2001) Multicultural Jurisdictions. Cambridge: Cambridge University Press.

Wolff, S (1995) Commentary on Martha Nussbaum: human capabilities, female human beings. In: M.C. Nussbaum and J. Glover (eds.), Women, Culture and Development. Oxford: Clarendon Press: 105-17. 